\title{
Tobacco Access and Availability for Vietnamese School Children (aged 13-15): Results from the Global Youth Tobacco Use Survey (GYTS) 2014 in Viet Nam
}

\author{
Le Thi Kim Anh ${ }^{1}$, Bui Thi Tu Quyen ${ }^{1 *}$,Hoang Van Minh ${ }^{1}$, Kim Bao Giang ${ }^{2}$, Phan \\ Thi Hai ${ }^{3}$, Doan Thu Huyen ${ }^{3}$, Luong Ngoc Khue ${ }^{3}$, Nguyen Tuan Lam ${ }^{4}$, Pham Thi \\ Quynh Nga ${ }^{4}$
}

\begin{abstract}
Efforts to reduce tobacco use among school children need to be based on understanding of access to cigarettes by these subjects because previous studies indicated that enforcement of laws for controlling tobacco sales seems to not affect teen/school children because they can obtain cigarettes from different sources. This paper aims to describe access to and availability of cigarettes among school students (aged 13-15 years old) according to the data from GYTS Vietnam 2014. In GYTS, a national school-based survey of students of grades 8-10, our findings showed that about $15 \%$ school children are current smokers who smoke at home, and that they could easily buy cigarettes from stores $(63.2 \%)$, or someone else $(27.8 \%)$, or street vendors $(9 \%)$. Notably, over $85 \%$ of school children answered that they were not refused because of their age. This high percentage was nearly the same in the North $(85.7 \%)$, the Centre $(\mathbf{9 2 . 5 \%})$, and the South $(\mathbf{8 9 . 7 \%})$ of Viet Nam. These findings show that it is quite easy for school children to obtain cigarettes and this is a crucial challenge for policy makers aiming to reduce tobacco use among youth in general and school-age students in particular.
\end{abstract}

Keywords: Access and availability - tobacco use - school children - GYTS - Vietnam

Asian Pac J Cancer Prev, 17 Tobacco Prevention and Control in Vietnam Suppl, 25-29

\section{Introduction}

Tobacco use is one of the most frequent risk factors of non-communicable diseases (NCD) in the world and in Vietnam with a high proportion of tobacco use among adult people, especially males (Yach et al., 2004, Ministry of Health et al., 2010). According to a report on comparative risk assessment of burden of disease in Vietnam, tobacco use causes $19.1 \%$ of dealths and $12.1 \%$ of the total burden of disease in 2008 (Ministry of Health et al., 2014).

Although the harm of tobacco use has been previously determined, the proportion of tobacco use has remained stable and even increased in developing countries. In Vietnam, according to Global Adult Tobacco Survey (GATS) Vietnam 2010, the proportion of tobacco use of males aged 15 and over was 47.4\%; and World Health Organisation (WHO) estimated that this proportion was 48\% in 2015 (Ministry of Health et al., 2010; World Health Organisation, 2015). Also in GATS, youth accounts for high proportion among all smokers in Vietnam; the survey indeed showed that the proportion of smokers aged less than 17 years was about 20\% (Ministry of Health et al.,
2010).

Like other countries in the world, one of reasons for the high proportion of tobacco use among young people is the availability and easy accessibility of cigarettes. Previous studies have shown that most young people who smoke buy cigarettes themselves in convenience stores or shop, kiosks, street vendors and grocery stores (Warren et al., 2000, Centers for Disease Control and Prevention, 2008). They are successful at purchasing cigarettes $40 \%$ to $70 \%$ of the time, and they purchase 1 billion packs of cigarettes each year. In Vietnam, Global Youth Tobacco Survey (GYTS) Vietnam in 2007 also identified that young people (e.g. secondary school students - aged 13-15 - as in GYTS) found it eay to buy cigarettes in a store.

In order to reduce the harmfulness of tobacco use, the Law on Prevention and Control of Tobacco of Vietnam harms was issused in 2012. According to this Law, youth (i.e. people aged less than 18 years old) is banned to sell, buy, and use cigarettes. In addition, selling or providing cigarettes to youth is also banned (Vietnam National Assembly 2012). However, previous experiences showed that enforcement of laws for controlling tobacco use among youth usually did not affect teen/school children 
smoking because they could get cigarette from several different sources such as street vendors, vending machines, and other people (Ling and Landman, et al., 2002). Therefore, the efforts of reducing tobacco use among youth in general and school children in particular need to base on understanding of the access to cigarette of these subjects. This paper aims to describe the access to and availability of cigarettes among school students (aged 13-15 years olds) under data of GYTS Vietnam 2014.

\section{Materials and Methods}

\section{Data source}

Data used in this paper was taken from the GYTS 2014 in Vietnam. The GYTS is a national school-based survey of students aged 13-15 years old (grade 8-10). In this survey, a two-stage cluster sample design was used to recruite a representative sample of students in this period of ages. As a result, 3430 students aged 13-15 were selected and interviewed by an adapted and translated questionnaire from the original version of the Core questionnaire provided by CDC. Details of the survey methodology were published elsesewhere (Giang et al., 2016).

\section{Outcome indicators and other measurements}

The GYTS questionnaire consists of 8 main components, including the prevalence of tobacco use, environment of tobacco use, access and availability of tobacco, cessation, knowledge and attitudes of students, and tobacco-related school curriculum. According to the Global Youth Tobacco Survey Collaborative Group, the access to and availability of cigarettes are defined by the 3 following indicators: (1) prevalence of current smokers (who smoked cigarettes during the past 30 days before the survey) who usually smoke at home, (2) prevalence of current smokers (who smoked cigarettes during the past 30 days before the survey) who purchased cigarettes in a store or shop/street vendor/kiosk/vending machine/ someone else/other ways, and (3) prevalence of current smokers (who smoked cigarettes during the past 30 days before the survey) were not being turned down when making a request for buying cigarettes although they were under the legal age (The Global Youth Tobacco Survey Collaborative Group 2002).

We calculated prevalence of school children (who are either smokers or non-smokers) who were not refused purchase because of their age. In addition, this paper uses a classification of economic status based on the amount of pocket money spent a week consisting of 4 levels: (1) No money; (2) Less than VND 20,000; (3) VND 20,000VND 50,000; and (4) From VND 50,000 and above; and three regions of habitation: (1) North; (2) Central; and (3) South (Giang et al., 2016).

\section{Data processing and analysis}

The paper uses data that were processed (scanning, cleaning, editing, and weighting) by CDC. Descriptive data analysis was done with the estimation of frequencies and percentages for different indicators. All analysis in the paper was conducted with final sampling weights. Because of the small sample size of the number of female school children who are current smokers, the first and second indicators of this paper would present for males. Only the third indicator would be analysed by both sexes.

\section{Ethical considerations}

The study was presented and discussed among those who are in charge of health research at the Ministry of Health and provincial authorities to get approval. Approval was also received from teachers, representatives of parents and students before carrying out survey.

\section{Results}

Altogether 3430 school children aged 13-15 years participated in the survey, 49.1 were males and $50.9 \%$ were females. The prevalence of tobacco smoking among the students was $3.5 \%, 6.3 \%$ among males and $0.9 \%$ among females (Giang et al., 2016).

The proportions of male students who were current smokers smoking at their home or their friends' house were high (15.1\% and $22.8 \%$, respectively). Moreover, about $15 \%$ of current smokers smoked at their school (Figure 1).

Table 1 indicates that the percentage of school children who were current smokers in the Central smokes at home, or at school, or at friends' house was much higher than those in the North and the South. Meanwhile, school children in the South do not seem to smoke at home, but the percentage of those who smoke at their friends' house was quite high $-31 \%$. Table 1 also shows school children aged 14 had lower percentage of smoking at home than those aged 13 and 15 (8.1\% compared to $17.4 \%$ and $17.1 \%$, respectively).

Generally, about $63 \%$ of current smokers could get cigarettes from stores or shops. Specifically, table 2 indicates a high proportion (about 74\%) of current smokers aged 15 getting cigarettes from stores. In addition, the percentage of current smokers in the South getting cigarettes from store/shops was higher than those in the North and the Central $(82.1 \%$ compared to $63.5 \%$ and $35.6 \%$, respectively).

On asking school students that during the past 30 days, did anyone refuse to sell school children cigarettes because of their ages, over $85 \%$ of school children $-87.3 \%$ for females and $94.5 \%$ for males - answered that they were not refused because of their age (Figure 2). Table 3 shows

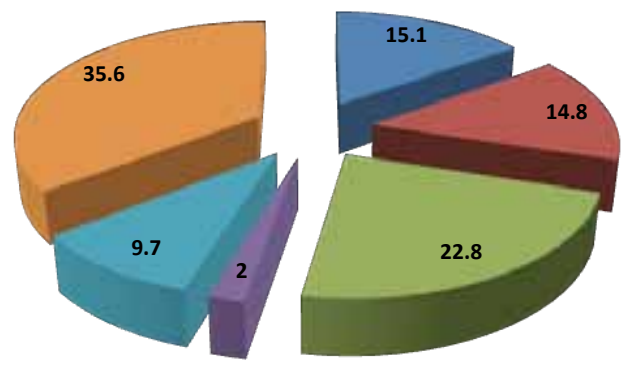

$\square$ At home $\square$ At school $\varpi$ At friends' house $\square$ At social events $\square$ In public spaces $\square$ Others

Figure 1. Percentage of Places of Smoking among School Children Males Aged 13-15 years who are Current Smokers in Vietnam 
Tobacco Access and Availability for Vietnamese School Children (aged 13-15): Results from the GYTS 2014 in Viet Nam

Table 1. Percentages of Places Where Smoking Occurred among School Children Males aged 13-15 years who are Current Smokers in Vietnam by age, Region, and Economic Levels

\begin{tabular}{|c|c|c|c|c|c|c|}
\hline Places of smoking & At home & At school & At friends' house & At social events & In public spaces & Others \\
\hline \multicolumn{7}{|l|}{$\overline{\text { Age }}$} \\
\hline 13 & 17.4 & 24.1 & 15.7 & 0 & 0 & 42.8 \\
\hline 14 & 8.1 & 19.3 & 27.2 & 0 & 3.8 & 41.6 \\
\hline 15 & 17.1 & 12 & 22.5 & 2.9 & 13 & 32.5 \\
\hline \multicolumn{7}{|l|}{ Region } \\
\hline North & 22.6 & 14.9 & 11.5 & 4.7 & 11.9 & 34.4 \\
\hline Centre & 26.6 & 27.8 & 31 & 0 & 0 & 14.6 \\
\hline South & 0 & 7.5 & 31 & 0 & 12.6 & 48.9 \\
\hline \multicolumn{7}{|c|}{ Economic levels (Weekly pocket money spent) } \\
\hline 1 & 19.8 & 11.7 & 11.2 & 9.9 & 21.8 & 25.6 \\
\hline 2 & 30.3 & 12.9 & 44.1 & 0 & 5 & 7.7 \\
\hline 3 & 13.1 & 9.6 & 29.2 & 0 & 6.2 & 41.9 \\
\hline 4 & 4.9 & 20.8 & 7.5 & 2.3 & 11.6 & 52.9 \\
\hline
\end{tabular}

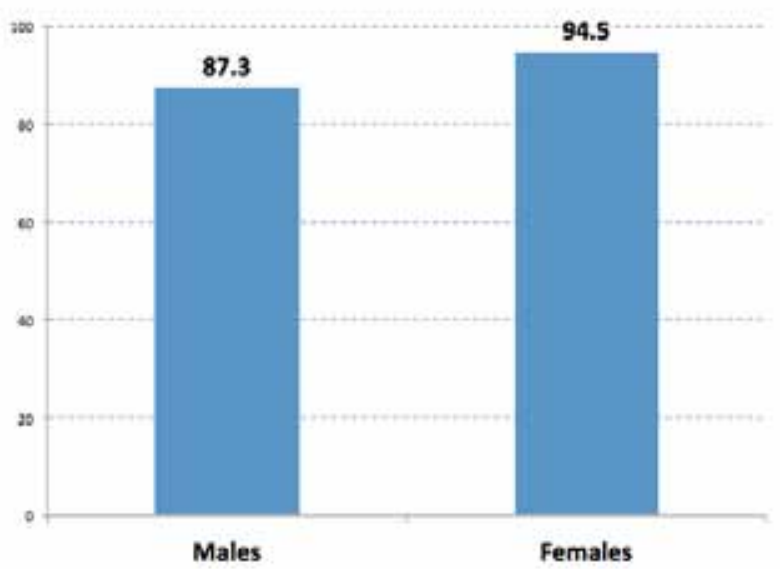

Figure 2. Prevalence of School Children Who Were Not Refused Purchase Because of their Age in Vietnam

Table 2. Percentages of Places of Buying/Getting Smoking among School Children Males Aged 13-15 years who are Current Smokers in Vietnam by Age, Region, and Economic Levels

\begin{tabular}{lccc}
\hline $\begin{array}{l}\text { Places of buying/ } \\
\text { getting cigarette }\end{array}$ & $\begin{array}{c}\text { Stores } \\
\text { /Shops }\end{array}$ & $\begin{array}{c}\text { Street } \\
\text { vendor }\end{array}$ & $\begin{array}{c}\text { Someone } \\
\text { else }\end{array}$ \\
\hline Age & 59.9 & 0 & 40.1 \\
13 & 28.5 & 26.7 & 44.8 \\
14 & 73.6 & 5 & 21.4 \\
15 & & & \\
Region & 63.5 & 3.2 & 33.3 \\
$\quad$ North & 35.6 & 14.1 & 50.3 \\
Centre & 82.1 & 11.5 & 6.4 \\
South & 51 & 35.3 & 13.7 \\
Economic levels (Weekly pocket money spent) & \\
1 & 55.9 & 0 & 44.1 \\
2 & 87.6 & 0 & 12.4 \\
3 & 61 & 11.8 & 27.2 \\
4 & 63.2 & 9 & 27.8 \\
\hline Total & & &
\end{tabular}

that this proportion is high in all the North $(85.7 \%)$, the Centre (92.5\%), and the South (89.7\%).

Table 3 also indicates that the highest percentage of being refused purchase cigarette because of their age is for those who have no money spent a week. Meanwhile, this percentage for those who have money is less than $10 \%$.
Table 3. Percentages of School Children Who Were Not Refused Purchase because of their Age in Vietnam by Age, Region and Economic Level

\begin{tabular}{lcc}
\hline $\begin{array}{l}\text { Places of buying/ } \\
\text { getting cigarette }\end{array}$ & Refused & $\begin{array}{c}\text { Not } \\
\text { refused }\end{array}$ \\
\hline Age & 6.8 & \\
13 & 13.1 & 93.2 \\
14 & 10 & 86.9 \\
15 & & 90 \\
Region & 14.3 & \\
North & 7.5 & 85.7 \\
Centre & 10.3 & 92.5 \\
South & 89.7 \\
Economic level (Weekly pocket money spent) & \\
1 & 23 & 77 \\
2 & 7.2 & 92.8 \\
3 & 9.1 & 90.9 \\
4 & 9.8 & 90.2 \\
\hline
\end{tabular}

\section{Discussion}

An analysis of GYTS data reveals that the rate of smoking in students aged $13-15$ is $3.5 \%$. Within this rate, $6.3 \%$ and $0.9 \%$ are male and female smokers, respectively. This result is similar to findings from other studies conducted in low and middle income countries (Zhao et al., 2015). However, it is still lower than a result of a study in America that $6 \%$ of students smoked within past 30 days (Arrazola et al., 2014). Moreover, there is growing evidence that male students are more likely to smoke compared to females (Arrazola et al., 2014, Zhao et al., 2015).

Reducing the accessibility to cigarettes is one of the most effective solutions to prevent young people from smoking (Dent and Biglan 2004; Turner et al., 2004). It is demonstrate that the prevalence of smokers is greater in settings where the students can easily buy cigarettes, and activities of illegal cigarette commercial happen at high rate.

According to paragraphs 4,5, and 6 of the article 9 in the Vietnamese law on prevention and control of tobacco harms (Vietnam National Assembly 2012), young people aged under 18 are not allowed to buy tobacco products. Similarly, salesmen are prohibited from selling these products to these young people. However, our study shows that the rate of students, who are refused to be 


\section{Le Thi Kim Anh et al}

sold tobacco-related products for use and other people, is relatively low. For example, $12 \%$ of females and $5 \%$ of males were not able to buy cigarettes. Interestingly, the reason is that they cannot afford to buy tobacco products rather than a reason of younger age. It suggests that the law enforcement may be not in a serious and strict manner, which is mostly due to weak monitoring and communication, as well as lack of strict punishment. This result is consistent with findings from other studies (Warren et al., 2008). In addition, the negative effect of weak law enforcement is indicated in some research (Turner et al., 2004, Marsh et al.,2012). More specifically, sales persons rarely refuse to sell cigarettes to almost all students, even these young people are wearing uniform. In other words, the students can easily buy cigarettes while the law has mentioned limited age. A research carried out by Marsh et al. (2012) illustrates that there is about $28 \%$ of students being asked about their ages when they try to access to products-related tobacco. More boys than girls are asked about their ages. The rate of students being refused decreased from $45 \%$ in 2000 to $28 \%$ in 2008 . This difference is statistical significant $(\mathrm{p}<0.001)$. Moreover, this author indicated that students are 6 times more likely to be refused if they are asked about their ages and student/personal identifications in compared to those without being asked. Therefore, to reduce the accessibility to cigarette products in students, there is a need on strengthening the enforcement of the Vietnamese law on prevention and control of tobacco harm in order to decrease heir exposure.

Our study reveals that well over $60 \%$ of students get cigarettes by buying or receive from friends and relatives. Other studies show the same results (Hughes et al., 2011, Leatherdale et al., 2011, Marsh et al., 2012, Donaghy et al., 2013) that illegal commercials, friends, relatives, and strangers are considered as sources of providing cigarettes for the students. It suggests that monitoring of law enforcement at the shops selling products-related tobacco is of vital importance. Along with it, communication in the community is seen as one of the most effective solutions to enable people understand that people aged less than 18 are not allowed to smoke.

There are some limitations in our study. Firstly, it used a self-reported questionnaire, so recall and information bias might be a problem. For instance, smoking in students might be estimated at low rate than the rate in reality. Secondly, due to the use of secondary data for analysis, the researchers are unable to examine the relationships between the accessibility to cigarettes and some potential factors. Thirdly, this study wa s conducted in students aged 13-15. Thus, the generalization of its findings is limited to those at the same ages, but not going to schools.

In conclusion, the findings from this study on the accessibility to cigarettes in students aged 13-15 in Vietnam show that these people can easily access cigarettes. Thus the Vietnamese law on prevention and control of tobacco harms that salesmen are not allowed to sell cigarettes to young people aged less than 18 is being broken.

\section{Acknowledgements}

The authors would like to thank the VINACOSH (Vietnam Steering Committee on Smoking and Health) and the GYTS team of Vietnam for making these data available. We also thank WHO's Tobacco Free Initiative (TFI) and CDC's Office on Smoking and Health for providing technical assistances. We acknowledge the financial supports and coordination of the Hanoi School of Public Health, World Health Organization and the Tobacco Control Research group of Vietnam Tobacco Control Fund. The authors declare that they have no competing interests.

\section{References}

Arrazola RA, Neff LJP, Kennedy SM, et al (2014). Tobacco Use Among Middle and High School Students - United States, 2013. Atlanta, U.S. Center for Disease Control, 1021-6.

Centers for Disease Control and Prevention (2008). Global Youth Tobacco Surveillance, 2000-2007. Surveillance Summaries.

Dent C, Biglan A (2004). Relation between access to tobacco and adolescent smoking. Tob Control, 13, 334-8.

Donaghy E , Bauld D, Eadie J, McKell B, Pringle A, Amos (2013). A qualitative study of how young Scottish smokers living in disadvantaged communities get their cigarettes. Nicotine Tobacco Res, 15, 2053-9.

Giang KB, Minh HV, Hai PT and et al (2016). Methodology of global youth tobacco use survey (GYTS) in Viet Nam, 2014. Asian Pac J Cancer Prev, 17 Tobacco Prevention and Control in Viet Nam Suppl, 11-15.

Hughes SK, Hughes K, Atkinson AM, Bellis MA, Smallthwaite L (2011). Smoking behaviour, access to cigarettes and relationships with alcohol in 15- and 16-year-old schoolchildren. Eur J Public Health, 21, 8-14.

Leatherdale ST, Ahmed R, Vu M (2011). Factors associated with different cigarette access behaviours among underage smoking youth who usually smoke contraband (native) cigarettes. Can J Public Health, 102, 103-7.

Ling PM, Landman A, Glantz SA (2002). It is time to abandon youth access tobacco programmes. Tobacco Control, 11, 3-6.

Marsh L, Gray A, McGee R, Newcombe R, Patterson R (2012). Access to cigarettes by young New Zealand smokers: little change from 2000 to 2008. Aus N Z J Public Health, 36, 415-20.

Ministry of Health, Hanoi Medical University and General Statistics Office of Vietnam (2010). Global adult tobacco survey: vietnam 2010. Hanoi, Vietnam.

Ministry of Health, Hanoi School of Public Health and Health Strategy and Policy Institute (2014). A comparative risk assessment of burden of disease in Vietnam. Hanoi, Vietnam.

The Global Youth Tobacco Survey Collaborative Group (2002). Tobacco use among youth: a cross country comparison.To Control, 11, 252-70.

Turner KM, Gordon J, Young R (2004). Cigarette access and pupil smoking rates: a circular relationship? Health Promotion Int, 19, 428-36.

Vietnam National Assembly (2012). The law on prevention and control of tobacco of vietnam harms. Hanoi, Vietnam.

Warren CW, Jones NR, Peruga A, et al (2008). Global Youth Tobacco Surveillance, 2000-2007. Morbidity and Mortality Weekly Report: Surveillance Summaries, 57, 1-27.

Warren CW, Riley L, Asma S, et al (2000). Tobacco use by youth: a surveillance report from the Global Youth Tobacco Survey project. Bull WHO, 78, 868-76. 
Tobacco Access and Availability for Vietnamese School Children (aged 13-15): Results from the GYTS 2014 in Viet Nam

World Health Organisation (2015). WHO global report on trends in prevalence of tobacco smoking 2015 WHO global report on trends in prevalence of tobacco smoking 2015: 1.Smoking - prevention and control. 2.Smoking - trends. 3.Smoking - epidemiology. WHO Press, World Health Organization, World Health Organization.

Yach D, Hawkes C, Gould CL, Hofman K J (2004). The global burden of chronic diseases, overcoming impediments to prevention and control. JAMA, 291, 2616-22.

Zhao L, Palipudi KM, Ramanandraibe N, Asma S (2015). Cigarette smoking and cigarette marketing exposure among students in selected African countries: Findings from the Global Youth Tobacco Survey. Prev Med, (Epub ahead of print]. 